\title{
Maximal expiratory flow-volume curves in Londoners aged 60 years and over
}

\author{
R W FOWLER, R A PLUCK, M R HETZEL \\ From the Departments of Geriatric Medicine and Chest Medicine, Whittington Hospital; and the Department of \\ Social Science, Royal Holloway and Bedford New College, London
}

ABSTRACT To obtain more accurate information about respiratory function in the elderly, we carried out spirometry and constructed maximum expiratory flow-volume curves in 136 volunteers over the age of 60 years (90 women, 46 men). Significant age related differences were found. Although vital capacity appeared well preserved in all groups, mid expiratory flow rates were low, even in lifelong non-smokers. On the basis of previous work, many of the subjects in this study would have been assessed as having small airways obstruction. The number of subjects is larger than in previous studies of airflow in this age group. Old people have often smoked, and many have a history of cardiovascular disease. Such individuals were included provided that they were fit and active for their age, and had no overt respiratory disease. It is argued that our findings will be of more clinical relevance to the elderly population than values derived either from population studies or studies that have used rigorous selection criteria to exclude subjects who smoked or had a history of non-respiratory disease.

Respiratory disease is common, and its prevalence increases with age. ${ }^{12}$ With rising numbers of very old people, medical practice must meet the need for accurate assessment of disease in this age group. Unfortunately, studies of lung function in normal people seldom include enough older subjects to predict lung volumes or flow rates confidently in the over 60 s. Normal values are often obtained by projecting from trends seen in samples of younger subjects. ${ }^{34}$

It has been suggested that the relationship between lung function and age is curvilinear. ${ }^{5}$ Longitudinal studies ${ }^{67}$ show that lung function starts to decline later than was previously thought, and that this deterioration accelerates with increasing age. The common practice of predicting normal values by linear extrapolation from younger groups is therefore suspect. It could overestimate lung function, which might have clinical consequences where lung function is being used as a guide to the risks of surgery or to assess patients with unexplained breathlessness.

Separate studies of the elderly ${ }^{8-11}$ have produced conflicting results. Two British studies ${ }^{8} 9$ report values for $F E V_{1}$ and forced vital capacity (FVC) that are

\footnotetext{
Address for reprint requests: Dr RW Fowler, Rush Green Hospital, Romford, Essex RM7 0YA.
}

Accepted 27 August 1986 almost a half litre lower than American values, ${ }^{11}$ though the way in which subjects were selected (and the inclusion of smokers) may be responsible. None of these studies report flow rates. The recent report from Knudson's group, ${ }^{12}$ including a separate analysis of the results from elderly women, is probably the best current source of reference values for this age group. This report also shows the discrepancies that arise (which appear to increase with age) when different recommendations ${ }^{13-15}$ are followed for the measurement of flow rates from the flow-volume curve. Schoenberg's study, ${ }^{5}$ which adopted a curvilinear relationship between lung function and age, is also relevant to this age group, though the numbers are small. Other studies ${ }^{1617}$ include too few elderly subjects and too little methodological detail for current use in this age group.

Our study tries to provide more information by reporting the results of spirometry and measurement of maximal expiratory flow in a volunteer group of healthy white Londoners aged 60 years and over. People who survive into old age rarely escape physical insults, and we have therefore included those with a history of non-respiratory disease. We have also included smokers, because lifelong non-smoking men are a small, possibly unrepresentative, fraction of the elderly population. 


\section{Methods}

SUBJECTS

We recruited subjects over the age of 60 years who were willing to take part in a series of tests of lung function. They came from adult education classes in the Boroughs of Camden and Islington, the City Literary Institute, the Civil Service Retirement Fellowship, the Women's Royal Voluntary Service, local bowls clubs, British Legion clubs, the Working Men's College, and other organisations for the elderly.

All subjects were asked about smoking habits, respiratory symptoms, past medical history, medication, and levels of physical activity. Each was examined, body measurements were made (see below), and chest radiographs were obtained (posteroanterior and left lateral views). Subjects were classed according to their medical state and smoking habits. Group A had no appreciable disease, group B were subjects reporting chronic non-respiratory disease, and group $\mathrm{C}$ had a history or radiological evidence of respiratory disease, such as asthma or tuberculosis. Subjects reporting cough and sputum alone were classified as normal (group A), as were subjects with apical pleural or small discrete parenchymal lesions on their chest radiographs. Smokers were those who had at any time smoked the equivalent of one pack a day for one year or more, regardless of their current habit.

\section{APPARATUS}

We used an 8 litre Ohio spirometer, connected to a flow-volume unit containing a differentiating circuit and internal calibrations (PK Morgan Ltd, Chatham, Kent). The spirometer record of volume against time was traced on paper. Flow and volume signals were also traced in "real time" with a Bryans 27000 series $\mathrm{X}-\mathrm{Y}$ recorder.

Ten curves produced by this method were compared with those generated with a microprocessor (Floop), and also with measurements on a Wright peak flow meter. For maximal expiratory flow at $50 \%$ FVC $\left(\mathrm{FEF}_{50}\right)$ and at 25\% FVC $\left(\mathrm{FEF}_{25}\right)$ the difference between our measurements and those from the Floop averaged less than $2 \%$. Our peak expiratory flow rates (PEF) corresponded closely with values obtained on the peak flow meter, though the Floop appeared to overestimate peak flow by $16 \%$ (this apparatus does not include any routine for "averaging" PEF over a set period).

Volume calibration was checked daily using a one litre calibration syringe. Flow calibration was performed weekly by using a vacuum cleaner motor (to produce constant air flow), rheostat, and rotameter connected in series to the spirometer.

TESTING PROCEDURE

Tests were carried out between 10.00 and 17.00 hours by a single investigator (RWF). Subjects were seated, and wore a noseclip. The manoeuvre was demonstrated and practised before the beginning of the test. The subject was instructed to breathe in to total lung capacity (TLC), attach a disposable mouthpiece to his or her mouth, and perform a maximum expiration to residual volume (RV), followed by a maximal inspiration back to TLC. This was repeated until either three loops of consistent shape had been obtained or the subject became tired. Spirometer traces and flow-volume plots were inspected after each attempt. Then $500 \mu \mathrm{g}$ of terbutaline were administered from a metered dose inhaler, with a spacing device (Nebuhaler, Astra Ltd) to minimise differences in inhalation technique. A minimum of two flow-volume manoeuvres were then performed after an interval of 15 minutes.

ANTHROPOMETRIC MEASUREMENTS

Standing height was measured with a stadiometer; traction was applied to the head to minimise postural differences. ${ }^{18}$ Sitting height was measured in the same way, a flat stool of known height being used. Body mass was measured, with the subject lightly clothed, by means of a calibrated beam balance. The degree of thoracic kyphosis was measured by the method of Milne and Lauder, 19 a surveyor's "flexicurve" being applied between the seventh cervical and first lumbar vertebrae. (This method allows the calculation of a "kyphosis index," which correlates well with radiological techniques for measuring age related kyphosis.) The percentage of body fat was estimated on the basis of the relationship between the sum of four skinfold thicknesses (Holtain skin fold calipers) and the percentage of body fat established by Durnin and Womersley. ${ }^{20}$

\section{DERIVING RESULTS}

$\mathrm{FEV}_{1}$ was measured manually by back extrapolation. The highest $\mathrm{FEV}_{1}, \mathrm{FVC}$, and PEF volumes and flow rates were used, even if they came from separate attempts. $\mathrm{FEF}_{50}$ and $\mathrm{FEF}_{25}$ were measured from the curve with the highest sum of $\mathrm{FEV}_{1}$ and FVC, though the curve was first carefully inspected to ensure that it $\mathrm{N}$ was a maximal effort. For a curve to be acceptable its PEF had to be within $10 \%$ of the greatest PEF value. Flows and volumes were corrected to body temperature, water saturation, and standard atmospheric pressure on the basis of measurements made on the day of testing. No additional correction was made to allow for warming of the spirometer.

Intraindividual variability was examined by randomly selecting 10 women in each age group, and using three to six well shaped curves from each subject with vital capacities within $10 \%$ of the maximal FVC, and calculating the mean within subject stan- $\underset{<}{\sigma}$ 
Table 1 Subjects analysed, classified by age, sex, and smoking habits (non-smokers have smoked less than one "pack-year"; ex-smokers are included with smokers)

\begin{tabular}{|c|c|c|c|c|c|c|c|}
\hline Age (y) & $60-65$ & $65-70$ & $70-75$ & $75-80$ & $80-85$ & $85+$ & Total \\
\hline \multicolumn{8}{|l|}{ MEN: } \\
\hline Non-smokers & 1 & 4 & 4 & 3 & 2 & & 14 \\
\hline Smokers & & & 9 & & & & ${ }^{32} 46$ \\
\hline \multicolumn{8}{|l|}{ WOMEN: } \\
\hline $\begin{array}{l}\text { Non-smokers } \\
\text { Smokers }\end{array}$ & 11 & $\begin{array}{r}10 \\
6\end{array}$ & $\begin{array}{r}14 \\
5\end{array}$ & $\begin{array}{l}\mathbf{6} \\
7\end{array}$ & $\begin{array}{l}8 \\
3\end{array}$ & $\begin{array}{l}4 \\
2\end{array}$ & \\
\hline Total & & & & & & & 136 \\
\hline
\end{tabular}
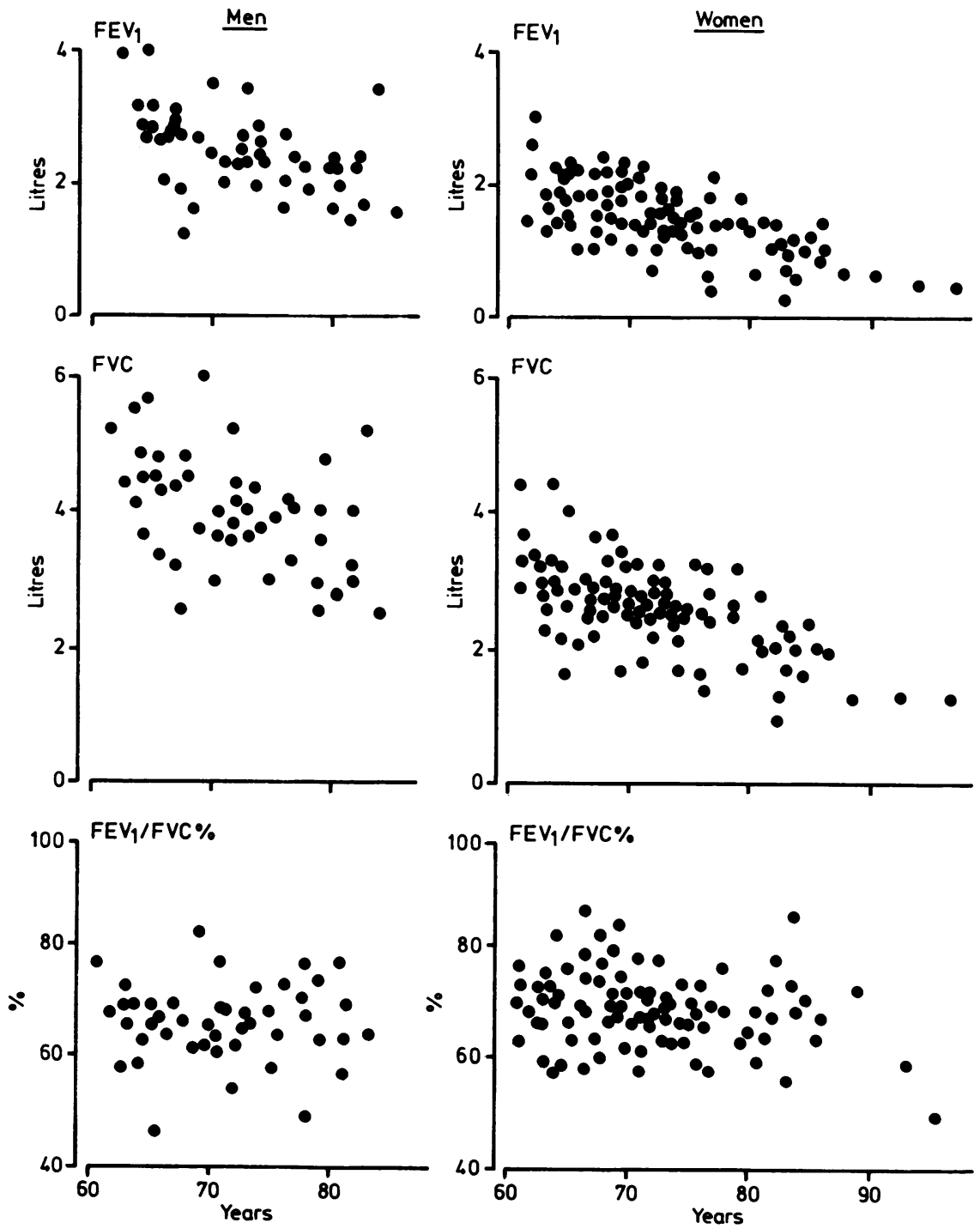

Fig $1 F E V_{1}$, forced vital capacity (FVC), and FEV $/ F V C \%$ in men and women aged 60 years and over. Smokers, ex-smokers, and non-smokers of both sexes are included. 

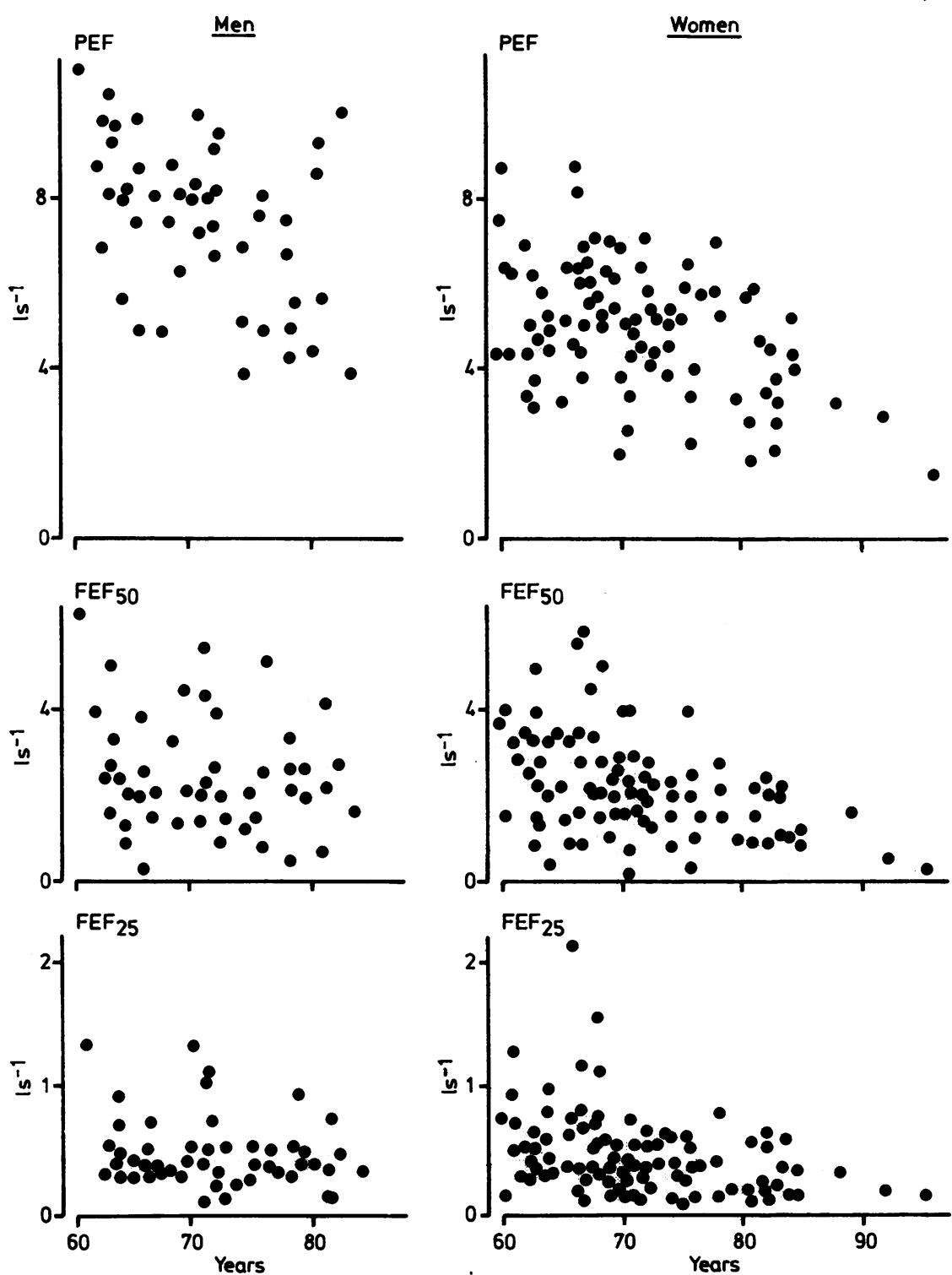

Fig 2 Peak expiratory flow ( $P E F$ ) and maximum expiratory flow $\left(F_{E} F_{50}\right.$ and $\left.F E F_{25}\right)$ in men and women aged 60 years and over. Smokers, ex-smokers, and non-smokers of both sexes are included.

dard deviations.

\section{STATISTICAL ANALYSIS}

Scatter plots of the raw data were first examined, and outlying values rechecked. Distributions were then examined for signs of conformity to standard distributions, and where appropriate transformations were considered. Multiple regression analyses were performed by a stepwise procedure. Analysis of variance was performed to determine the statistical significance of the multiple correlation coefficient and each regression coefficient. Where important predictor variables were correlated, partial correlations were calculated to investigate the nature of the interaction. Plots of residual values against fitted values and predictor variables were made.

Where-curvilinear relationships appeared to exist, polynomial expressions and transformations were tested to see whether they improved the fit of the regression equation. To allow for the fact that decline 
Table 2 Linear regression equations on age and stature for spirometric indices and measurements of maximal expiratory flow (lower limit of normal is predicted value minus $1.645 \times$ SEE)

\begin{tabular}{|c|c|c|c|c|c|c|}
\hline & & \multicolumn{2}{|c|}{ Coefficients on age and stature } & \multirow[b]{2}{*}{ Constant term } & \multirow{2}{*}{$\begin{array}{l}\text { Standard error } \\
\text { of estimate }\end{array}$} & \multirow{2}{*}{$\begin{array}{l}\text { Multiple } \\
\text { correlation } \\
\text { coefficients }\end{array}$} \\
\hline & & $(y)$ & $(m)$ & & & \\
\hline \multicolumn{7}{|l|}{$\operatorname{MEN}(n=46)$ : } \\
\hline PEF & $\left(1 s^{-1}\right)$ & $-0 \cdot 126$ & $8 \cdot 75$ & 1.94 & $1 \cdot 56$ & 0.552 \\
\hline FVC & (l) & -0.057 & $5 \cdot 34$ & -0.73 & 0.74 & 0.573 \\
\hline $\mathrm{FEV}_{1}$ & (l) & -0.041 & 2.91 & 0.88 & 0.53 & $0 \cdot 540$ \\
\hline $\mathrm{FVC}^{*}$ & $\left(1 / m^{2}\right)$ & -0.020 & & $2 \cdot 89$ & $0 \cdot 248$ & 0.469 \\
\hline \multirow{2}{*}{\multicolumn{7}{|c|}{ ALLWOMEN $(n=87) \dagger$}} \\
\hline & & & & & & \\
\hline PEF & $\left(1 \mathrm{~s}^{-1}\right)$ & -0.055 & $7 \cdot 30$ & $-2 \cdot 38$ & 1.22 & $0 \cdot 515$ \\
\hline $\mathrm{FEF}_{50}$ & $\left(1 \mathrm{~s}^{-1}\right)$ & -0.070 & - & $7 \cdot 44$ & 1.04 & 0.426 \\
\hline $\mathrm{FEF}_{25}^{50}$ & $\left(1 s^{-1}\right)$ & -0.017 & - & $1 \cdot 72$ & 0.30 & 0.366 \\
\hline $\mathrm{FVC}^{25}$ & (l) & -0.039 & $4 \cdot 20$ & -0.98 & 0.44 & 0.724 \\
\hline $\mathrm{FEV}_{1}$ & (l) & -0.032 & 2.90 & -0.22 & $0 \cdot 36$ & 0.692 \\
\hline $\mathrm{FVC}^{*}$ & $\left(1 / \mathrm{m}^{2}\right)$ & -0.016 & & $2 \cdot 30$ & 0.171 & 0.554 \\
\hline $\mathrm{FEV}_{1}^{*}$ & $\left(1 / \mathrm{m}^{2}\right)$ & -0.013 & & 1.76 & $0 \cdot 142$ & 0.544 \\
\hline \multicolumn{7}{|c|}{ WOMEN: NON-SMOKERS $(n=53) \dagger$} \\
\hline PEF & $\left(1 s^{-1}\right)$ & -0.059 & $7 \cdot 29$ & -1.87 & $1 \cdot 13$ & 0.526 \\
\hline $\mathrm{FEF}_{50}$ & $\left(1 s^{-1}\right)$ & -0.072 & - & 7.81 & 0.94 & 0.456 \\
\hline $\mathrm{FEF}_{25}^{30}$ & $\left(1 s^{-1}\right)$ & -0.012 & - & $1 \cdot 35$ & 0.27 & $0 \cdot 286$ \\
\hline $\mathrm{FVC}^{25}$ & (l) & -0.042 & $4 \cdot 34$ & -0.93 & 0.39 & 0.760 \\
\hline FEV & (l) & -0.033 & 2.69 & 0.23 & 0.32 & 0.705 \\
\hline $\mathrm{FVC}^{*}$ & $\left(1 / m^{2}\right)$ & -0.017 & & 2.41 & 0.151 & 0.610 \\
\hline $\mathrm{FEV}_{1}^{*}$ & $\left(1 / \mathrm{m}^{2}\right)$ & -0.013 & & 1.77 & 0.125 & 0.563 \\
\hline \multicolumn{7}{|c|}{ WOMEN: SMOKERS $(n=34)$} \\
\hline PEF & $\left(1 \mathrm{~s}^{-1}\right)$ & -0.052 & $7 \cdot 29$ & -2.87 & 1.31 & 0.527 \\
\hline $\mathrm{FEF}_{50}$ & $\left(1 \mathrm{~s}^{-1}\right)$ & -0.070 & - & $7 \cdot 10$ & $1 \cdot 13$ & 0.431 \\
\hline $\mathrm{FEF}_{25}$ & $\left(1 \mathrm{~s}^{-1}\right)$ & -0.018 & $1 \cdot 60$ & -0.78 & $0 \cdot 33$ & 0.547 \\
\hline $\mathrm{FVC}^{25}$ & (l) & -0.036 & $4 \cdot 06$ & -1.06 & 0.50 & 0.703 \\
\hline $\mathrm{FEV}_{1}$ & (l) & -0.033 & 3.09 & -0.63 & 0.39 & 0.721 \\
\hline $\mathrm{FEV}_{1}^{1} / \mathrm{FVC}^{2} \%$ & & -0.372 & - & 95.5 & $6 \cdot 5$ & 0.401 \\
\hline $\mathrm{FVC}^{*}$ & $\left(1 / m^{2}\right)$ & -0.015 & & $2 \cdot 18$ & $0 \cdot 193$ & 0.517 \\
\hline $\mathrm{FEV}_{1} *$ & $\left(1 / \mathrm{m}^{2}\right)$ & -0.014 & & 1.77 & $0 \cdot 153$ & 0.578 \\
\hline
\end{tabular}

*Volumes divided by stature squared, according to Cole's simplified regression formula ${ }^{21}$ : FVC or FEV Ftature $^{2}(a+b$.age $)$.

+ Three oldest female subjects (all non-smokers) omitted (see text). Correlation and regression coefficients reach statistical significance $(\mathrm{p}<0.05)$. Non-significant regression coefficients have been omitted.

PEF, peak expiratory flow; FVC, forced vital capacity; $\mathrm{FEF}_{50}, \mathrm{FEF}_{25}$, maximum expiratory flow at $50 \%$ and $25 \%$. of vital capacity.

Table 3 Regression equations including transformations and alternative predictor variables, listed in order of their statistical importance

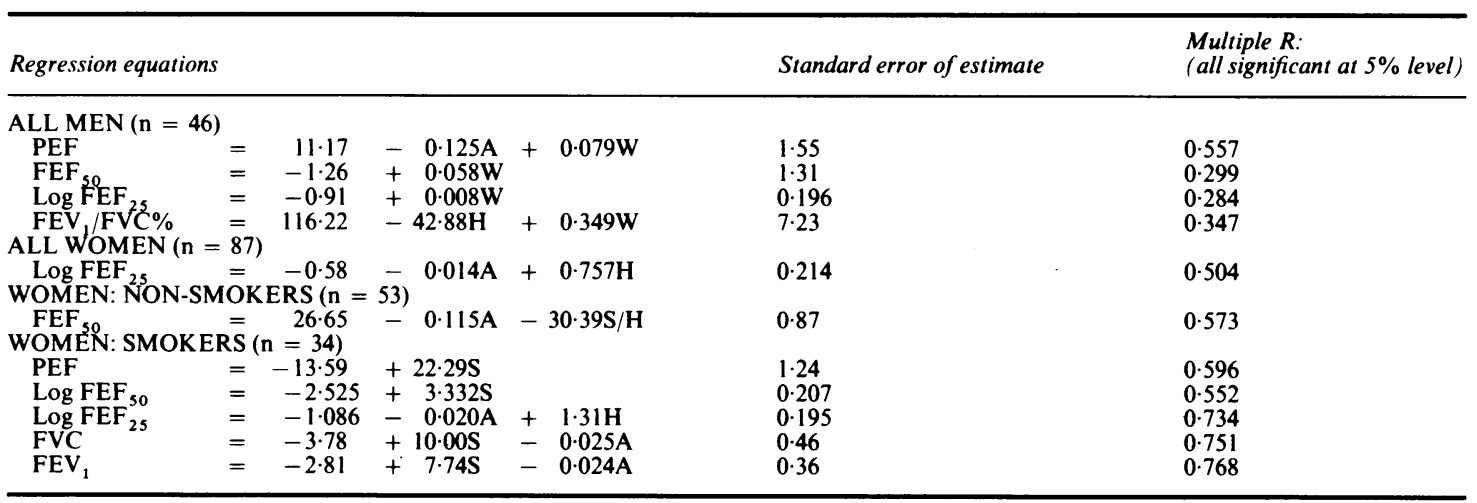

A, age in years; $H$, stature $(\mathrm{m}) ; \mathrm{W}$, body mass $(\mathrm{kg}) ; \mathrm{S}$, sitting height $(\mathrm{m}) ; \mathrm{S} / \mathrm{H}$, sitting height divided by stature.

For other abbreviations see table 2 .

in lung function is proportional to body size, we divided $\mathrm{FEV}_{1}$ and $\mathrm{FVC}$ by the square of stature ${ }^{21}$ to see whether this was superior to standard multiple regression on age and height in predicting these indices. A similar technique was tried in the analysis of flow rates.

\section{Results}

One hundred and sixty eight subjects volunteered -57 
men and 111 women. Fifteen subjects with respiratory disease (group C) were excluded. Thirty eight subjects had other chronic conditions (group B): 14 were hypertensive, 10 had a history of ischaemic heart disease, three had had cerebrovascular accidents, and 11 various other problems. Since there were no significant differences in lung function between subjects in groups $\mathbf{A}$ and $\mathbf{B}$, those with chronic nonrespiratory problems were not automatically excluded. Six were excluded because they took $\stackrel{x}{ }$ $\beta$ adrenergic blocking drugs and a further seven women (mean age 75.6 years) were excluded because of inability to produce satisfactory forced expiratory flow volume (FEFV) curves.

Seven men and 20 women showed more than $10 \% \stackrel{\vec{\nabla}}{\vec{D}}$ improvement in FEV 1 or FVC after bronchodilation. Their records were examined individually, and in कs some cases the apparent improvement was explained $\overrightarrow{0}$
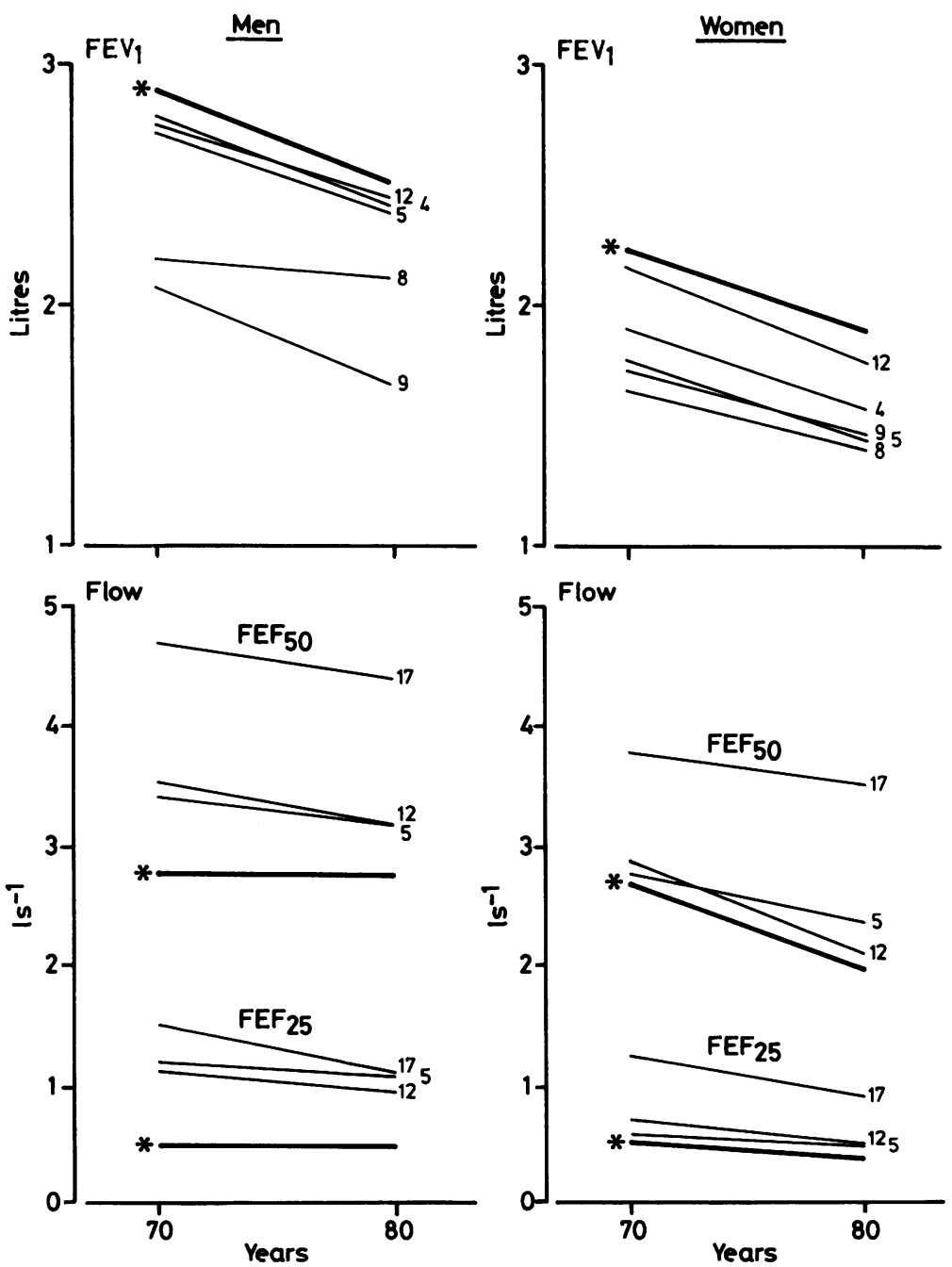

Fig 3 Predicted values for $F E V_{1}$ and maximum expiratory flow $\left(F E F_{50}\right.$ and $\left.F E F_{25}\right)$ in men and women aged 70-80 years. Mean predicted values from the present study (women all lifelong non-smokers, but male group includes smokers and non-smokers) are compared with those from previous studies. Values are calculated for men with a height of $1.7 \mathrm{~m}$ and weight of $70 \mathrm{~kg}$ and for women of $1.6 \mathrm{~m}$ and $60 \mathrm{~kg}$. Numbers refer to references: ${ }^{4}$-Berglund et al (smoking habits unspecified); 5 -Schoenberg et al (lifelong non-smokers); ${ }^{8}$--Milne and Williamson ( $8 \%$ of men and $73 \%$ of women were non-smokers); 9 -Burr et al (14\% of men and $72 \%$ of women were non-smokers); ${ }^{12}$-Knudson et al (lifelong non-smokers); ${ }^{17}$-Cherniack and Raber (current non-smokers). 
by failure to reach TLC or RV, or inadequate effort at these points in the initial attempts. Only two men and two women were excluded because their records showed unequivocal reversibility. For most subjects the measurements used were obtained before administration of the bronchodilator.

The analysis therefore includes 90 women (mean age 71.9 years, height $1.6 \mathrm{~m}$, and weight $61.7 \mathrm{~kg}$ ) and 46 men (mean age 71.3 years, height $1.7 \mathrm{~m}$, and weight $71.6 \mathrm{~kg}$ ). Table 1 shows the age distribution of this sample, dividing them into smokers (past or current) and lifelong non-smokers. Twenty four women and 14 men had a history of non-respiratory disease (group B). Twenty nine men $(51 \%)$ and 37 women $(33 \%)$ produced sputum at least occasionally, though only 13 men and 10 women met the Medical Research Council criteria for chronic bronchitis. Eighty three per cent had lived in London during periods of severe atmospheric pollution (before the 1956 Clean Air Act) and $60 \%$ were lifelong Londoners.

The results obtained are illustrated in figures 1 and 2. The three oldest women (aged 90, 93, and 96 years) were excluded from the regression analyses in tables 2 and 3. Figure 1 shows that their ages are extreme compared with the rest, and we thought that there were insufficient numbers in this age category to include them safely with the rest of the sample. Their removal was therefore intended to make the analysis more robust. The age and multiple correlation coefficients were reduced as a result. For example, in the case of PEF in non-smokers the age coefficient fell from -0.087 to -0.059 , and the multiple $\mathrm{R}$ from 0.615 to 0.526 . In most other cases, however, the changes were smaller, and the form of the equations remained unchanged.

$\mathrm{FEV}_{1} / \mathrm{FVC} \%$ and $\mathrm{FEF}_{50}$ were lower in female smokers than non-smokers $(\mathrm{p}<0.025$ and $<0.05$ respectively, using unpaired $t$ tests), though other indices did not appear to be significantly affected by smoking habit. Separate equations are given for female smokers (former or current) and lifelong nonsmokers (tables 2 and 3). There were too few male non-smokers for their data to be analysed separately.

Flow rates in all groups were positively skewed, particularly at low flow rates and in female smokers. The records of subjects with high flow rates were therefore re-examined to exclude measurement error, but in only one case was this a possible explanation for the high value. Removal of this subject made no significant difference to the regression equations. Positive skewing was especially apparent when residuals were examined. Logarithmic transformations were used to reduce this, and they improved the regression fits. Table 3 therefore uses logarithmic transformation for $\mathrm{FEF}_{25}$ in all groups and for $\mathrm{FEF}_{50}$ in female smokers. Table 3 also introduces other inde-

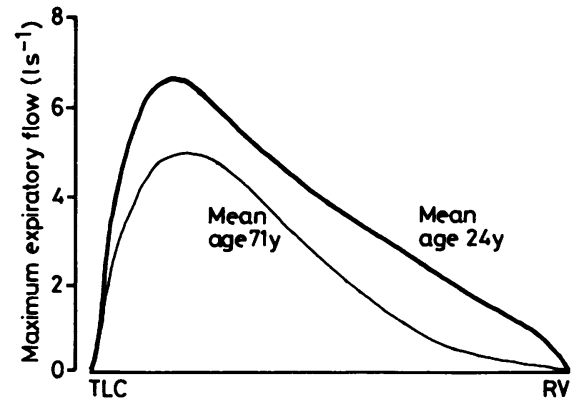

Fig 4 Composite maximal expiratory flow-volume curves from 10 old (mean age 71 years) and 10 young (mean age 24 years) non-smoking female subjects. The horizontal axis is normalised to percentage of vital capacity. TLC-total lung capacity; $R V$-residual volume.

pendent variables, showing that body weight (in men), sitting height (in women smokers), and the ratio of sitting to standing height (women nonsmokers) can be used to improve prediction.

In our sample of subjects Cole's method ${ }^{21}$ of analysis proved no better than standard multiple regression. Body fat content and measurement of kyphosis did not reduce variability in any of the groups.

Intraindividual variability was small by comparison with overall variability. The mean within subject standard deviations for women were $0 \cdot 32,0 \cdot 26$, $0 \cdot 11 \mathrm{~s}^{-1}$ for PEF, $\mathrm{FEF}_{50}$, and $\mathrm{FEF}_{25}$ respectively, and 0.059 and 0.086 litres for $\mathrm{FEV}_{1}$ and FVC, compared with between subject SDs of $1 \cdot 5,1 \cdot 22$, and $0 \cdot 38$ $1 / \mathrm{s}^{-1}$, and 0.490 and 0.6271 . Age and within subject variability did not appear to be related, though above the age of 85 years no subject produced more than two satisfactory efforts. The average age of the seven women who failed to produce any satisfactory efforts was 75.6 years, which was not significantly higher than the average age of the remainder ( $72 \cdot 0$ years).

Figure 3 compares predictions derived from our regression equations with predictions from previous studies. Figure 4 demonstrates age differences in maximal expiratory flow by comparing composite curves from a random sample of our non-smoking women with those from non-smoking female medical students.

Further details of results and statistical analyses may be obtained from the first author.

\section{Discussion}

By comparison with previous series (fig 3), our subjects show well preserved spirometric performance but low mid expiratory flow rates. On the basis of criteria of abnormality used in previous studies, only two ${ }^{1217}$ would classify any of our subjects as having 
an abnormally low FVC. The large difference between our spirometric values and those of two studies of British elderly subjects ${ }^{89}$ is particularly surprising. Although our predictions for $\mathrm{FEF}_{50}$ and $\mathrm{FEF}_{25}$ in female lifelong non-smokers are close to those of Knudson et al, ${ }^{12}$ another source ${ }^{17}$ would define $74 \%$ of our female lifelong non-smokers as having abnormally low $\mathrm{FEF}_{50}$. This suggests that previous studies have overestimated flow rates in older people, while underestimating spirometric indices.

The methods used may explain some of these differences. Neither of the previous British studies ${ }^{89}$ explains exactly how $\mathrm{FEV}_{1}$ and FVC were calculated from the volume-time trace. Both studies used mean values for $\mathrm{FEV}_{1}$ and $\mathrm{FVC}$, whereas we used the best measurement. A particular danger in studies that do not measure flow rates is that poor effort early in expiration, and especially premature termination of expiration, may be overlooked. We believe this to be a problem in studies of the elderly. It may have occurred in the study of Milne and Williamson, ${ }^{8}$ as the $\mathrm{FEV}_{1} / \mathrm{FVC}$ ratios are unusually high. Our results are much closer to those of Knudson et al, ${ }^{12}$ and this may be because we followed their methods for deriving $\mathrm{FEV}_{1}$ and $\mathrm{FVC}$.

We investigated the effect of our practice of using "best" rather than mean values. In our data on women "best" values were only 3-4\% higher than mean values, with a slight tendency for this discrepancy to increase with age. The reason that mean values are usually preferred is that, once practice attempts are eliminated, results of repeated attempts are randomly distributed. ${ }^{22}$ This may not apply in older subjects, in whom slower learning and fatigue could result in negative skewing. We therefore chose to retain "best" values, and believe that this is still common clinical practice.

Methods also affect flow measurement. The flow rates from our women were similar to the results of Knudson et al. ${ }^{12}$ Knudson's group compared their results based on the "best curve" method (the single curve with the highest sum of FEV 1 and FVC) with their earlier analysis, ${ }^{23}$ which used the envelope method and showed significant differences that increased with age. Because curves are superimposed, the envelope method conceals the fact that higher flow rates later in expiration may come from curves with initial submaximal effort. In our subjects the difference between the two methods for $\mathrm{FEF}_{50}$ and $\mathrm{FEF}_{25}$ was only about $5 \%$, but it may have been small because we had already eliminated obvious submaximal attempts.

The "best curve" method does not entirely solve the problem of selecting submaximal curves. In our analysis a submaximal curve would have been selected in six out of 46 men and eight out of 89 women if we had used this method alone. This is because back extrapolation can compensate for lack of effort early in expiration, and yield a falsely high $\mathrm{FEV}_{1}$. A relaxed effort can also lead to a higher FVC where there is reduced elastic recoil, as occurs with ageing. ${ }^{24}$ We therefore believe that it is important that flow-volume curves are rigorously inspected before analysis, to avoid selecting a visually unsatisfactory curve on spirometric criteria. We suggest the additional criterion of a PEF within $10 \%$ of maximal PEF.

Subject selection could be another factor explaining our high values for $\mathrm{FEV}_{1}$ and FVC by comparison with those of previous British studies. ${ }^{89} \omega$ Milne and Williamson ${ }^{8}$ and Burr et $a l^{9}$ both tested random samples of elderly people living at home. No attempt was made in these studies to exclude people with respiratory disease. Their results are average values for a population, who are not necessarily "normal". There is much disease in the elderly population, which may go undiagnosed. Epidemiological studies have found the following prevalences: asthma$6.5 \%{ }^{25}$; chronic bronchitis $44 \%$ in men and $17 \%$ in women ${ }^{26}$; and respiratory abnormality on chest radiography $-42 \%$ in men and $20 \%$ in women. ${ }^{27} \mathrm{We}$ found lower prevalences in our own sample, because we sought only volunteers who regarded themselves as "fit and healthy" for their years. Despite this we found, and excluded, 19 (11\% of the total sample) with respiratory disease. These included those with a history of respiratory disease (especially asthma or tuberculosis) or abnormal chest radiographs, and those found to have reversibility of airways obstruction when tested. They had a mean $\mathrm{FEV}_{1}$ that was $25 \%$ lower than the mean of the rest of the sample. The values of Milne and Williamson and of Burr et al may be lower because they are average values for random samples of populations containing appreciable numbers of people with respiratory disease.

There are further factors that explain our higher values. Our subjects were well motivated, which may not be the case when subjects are randomly selected from the general population. Furthermore, we tested them in a laboratory, which may have made them more compliant. Our method of inspecting flow-volume curves after each attempt, and correcting mistakes, may also have improved our results.

The inclusion of smokers may explain the fact that our men had lower flow rates than those in other stud- ? ies. Since we studied a fit subsection of the male $\square$ elderly population, lifelong non-smokers are probably even less common than our sample would suggest. The difficulty in recruiting such a group is illustrated by the small numbers of elderly men in Knudson's

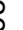


group, who started with a population survey. It is important to predict normal values for smokers, as most patients with respiratory disease have a smoking history. This need is emphasised in a recent report on lung function testing. ${ }^{13}$ Unfortunately, smokers are not a homogeneous group; a considerable proportion will develop airflow obstruction, and the selection criteria will determine how many of these affected individuals are present in a sample. Variability in our sample was higher in female smokers than non-smokers (coefficient of variation for $\mathrm{FEF}_{50}$ was $60 \%$ in female smokers compared with $41 \%$ in non-smokers).

Our regression analyses show that in women $50 \%$ of the variability in $\mathrm{FEV}_{1}$ and $\mathrm{FVC}$ can be explained by age and stature, as in younger age groups. The lower explained variance in the men $(23 \%)$ is probably due to the mixture of smokers and non-smokers. Age and height accounted for about $28 \%$ of the variability in PEF in all groups, though they proved less satisfactory predictors at lower flow rates, particularly in men. In this group body weight is the only measurement that significantly reduces variance in $\mathrm{FEF}_{50}$ and $\mathrm{FEF}_{25}$, suggesting an effect of muscularity.

In female smokers sitting height, though regarded as less reproducible than stature, was the more powerful predictor. Alone, it accounted for around 37\% of the variance in $\mathrm{FEV}_{1}$ and FVC, and $36 \%$ and $29 \%$ of variance in PEF and log $\mathrm{FEF}_{50}$ respectively. The importance of age as a predictor was therefore reduced. This finding was not seen in non-smokers, in whom the mean values and distributions of sitting height and stature were very similar. It suggests that in smokers the factors responsible for variations in sitting height have a greater effect on lung function. They may include osteoporotic vertebral collapse, since bone loss is thought to be faster in smokers.

In non-smokers variability in $\mathrm{FEF}_{50}$ was inversely proportional to sitting height, once the effects of age and stature had been removed (partial correlation $-0.333, p<0.025$ ). The same effect was observed for $\mathrm{FEF}_{25}$, though it did not reach the required level of significance. If the ratio of sitting height to stature was used, then stature exerted no independent effect at all. This means that a low ratio of sitting height to stature is associated with higher flow rates. Since the relationship does not apply to $\mathrm{FEV}_{1}$ and FVC, it suggests that restriction of chest wall movement (due to its reduced compliance in old age) may be responsible. Strapping the chest wall has been observed to produce similar changes in spirometry and flow. ${ }^{28}$

Knudson et $a l^{12}$ defined the lower limit of normal as that value above which the results of $95 \%$ of the normal population lie. The confidence limits quoted in their paper use the assumption that larger values have a larger variance, which for FEV 1 and FVC is unjustified. ${ }^{29}$ If skewed distributions are transformed to "normalise" their shape, we suggest that the subtraction of 1.645 SEE may still be used to estimate the lower limit of normal.

In general, our findings in an older urban population are consistent with those of Knudson et al, particularly for women. Although they studied a population sample, a rigorous screening process was used and only $37 \%$ of those tested satisfied their criteria of "normality." Presumably the highest proportion was rejected in the older age group. Although this adds strength to their findings of lower values for flow in the elderly, it is doubtful whether such selection is justified in this age group. An appreciable proportion are no longer "normal" in the medical sense, yet appear healthy and active. Our study includes such subjects, because we regard them as part of the fit elderly population. On the other hand, we were careful to exclude subjects with respiratory disease. Our results suggest that epidemiological studies including such subjects have underestimated "normal" spirometric values in this age group. These studies may be appropriate sources of reference values in young adults, but in the elderly we believe that normal values for clinical lung function testing should come only from those found to have no appreciable respiratory disease.

Our results also show important age related differences in the shape of the maximal expiratory flow-volume curve, illustrated in figure 4. Studies that underestimate this effect may, if used as a basis for predicting lung function in this age group, mislead the physician into diagnosis of small airways obstruction. We have found that even in lifetime non-smokers, an "obstructive" pattern in the MEFV curve may be normal in old age.

\section{References}

1 Ferris BG Jr, Anderson DO. The prevalence of chronic respiratory disease in a New Hampshire town. Am Rev Respir Dis 1962;86:165-77.

2 Lebowitz MD, Knudson RJ, Burrows B. Tuscon epidemiologic study of obstructive lung diseases. I: Methodology and prevalence of disease. Am J Epidemiol 1975; 102:137-52.

3 Kory RC, Callahan R, Boren HG, Syner JC. The Veterans Administration-Army Cooperative Study of pulmonary function. I: Clinical spirometry in normal men. Am J Med 1961;30:243-58.

4 Berglund E, Birath G, Bjure J, et al. Spirometric studies in normal subjects. I: Forced expirograms in subjects between 7 and 70 years of age. Acta Med Scand 1963;173:185-92. 
5 Schoenberg JB, Beck GJ, Bouhuys A. Growth and decay of pulmonary function in healthy blacks and whites. Respir Physiol 1978;33:367-93.

6 Glindmeyer HW, Diem JE, Jones RN, Weill H. Noncomparability of longitudinally and cross-sectionally determined annual change in spirometry. Am Rev Respir Dis 1982;125:544-8.

7 Krumpe PE, Knudson RJ, Parsons G, Reiser K. The aging respiratory system. In: Geokis $\mathrm{MC}$, ed. The aging process. Clin Ger Med 1985;1:143-75.

8 Milne JS, Williamson J. Respiratory function tests in older people. Clin Sci 1972;42:371-81.

9 Burr ML, Phillips KM, Hurst DN. Lung function in the elderly. Thorax 1985;40:54-9.

10 Ericsson P, Irnell L. Spirometric studies of ventilatory capacity in elderly people. Acta Med Scand 1969;185:179-84.

11 Schmidt CD, Dickman ML, Gardner RM, Brough FK. Spirometric standards for healthy elderly men and women. Am Rev Respir Dis 1973;108:933-9.

12 Knudson RJ, Lebowitz MD, Holberg CJ, Burrows B. Changes in the normal maximal expiratory flow-volume curve with growth and aging. Am Rev Respir Dis 1983;127:725-34.

13 Quanjer PH, ed. Standardized lung function tests. Bull Eur Physiopathol Respir 1983;19(suppl 5):1-94.

14 Ferris BG (principal investigator). Epidemiology Standardization Project. Am Rev Respir Dis 1978;118:55-88.

15 American Thoracic Society statement. Snowbird Workshop on Standardization of Spirometry. Am Rev Respir Dis 1979;119:831-8.

16 Bass $\mathrm{H}$. The flow volume loop: normal standards and abnormalities in chronic obstructive pulmonary disease. Chest 1973;63:171-6.

17 Cherniack RM, Raber MB. Normal standards for venti- latory function using an automated wedge spirometer. Am Rev Respir Dis 1972;106:38-46.

18 Cotes JE. Lung function. 4th edn. Oxford: Blackwell Scientific Publications, 1979:50.

19 Milne JS, Lauder IJ. Age effects in kyphosis and lordosis in adults. Ann Hum Biol 1974;1:327-37.

20 Durnin JVGA, Womersley J. Body fat assessed from total body density and its estimation from skinfold thickness: measurements on 481 men and women aged from 16 to 72 years. Br $J$ Nutr 1974;32:77-97.

21 Cole TJ. Influence of height on decline in ventilatory function. Int J Epidemiol 1974;3:145-52.

22 Ullah MI, Cuddihy V, Saunders KB, Addis GJ. How many blows really make an $\mathrm{FEV}_{1}, \mathrm{FVC}$, or PEFR? Thorax 1983;38:113-8.

23 Knudson RJ, Slatin RC, Lebowitz MD, Burrows B. The maximal expiratory flow-volume curve: normal standards, variability, and effects of age. Am Rev Respir Dis 1976;113:587-600.

24 Gibson GJ, Pride NB. Lung distensibility. Br J Dis Chest 1976;70:143-84.

25 Burr ML, Charles TJ, Roy K, Seaton A. Asthma in the elderly: an epidemiological survey. $\mathrm{Br} \mathrm{Med} J \mathrm{~J}$ 1979;1:1041-4.

26 Milne JS, Maule MM, Williamson J. Method of sampling in a study of older people with a comparison of respondents and non-respondents. Br J Prev Soc Med 1971;25:37-41.

27 Caird FI, Akhtar AJ. Chronic respiratory disease in the elderly: a population study. Thorax 1972;27:764-8.

28 Stubbs SE, Hyatt RE. Effect of increased lung recoil pressure on maximal expiratory flow in normal subjects. J Appl Physiol 1972;32:325-31.

29 Sobol BJ, Sobol PG. Per cent of predicted as the limit of normal in pulmonary function testing: a statistically valid approach [Editorial]. Thorax 1979;34:1-3. 